\title{
Review Article \\ Pathology of Acute Henipavirus Infection in Humans and Animals
}

\author{
K. T. Wong ${ }^{1}$ and K. C. Ong ${ }^{2}$ \\ ${ }^{1}$ Department of Pathology, Faculty of Medicine, University of Malaya, 50603 Kuala Lumpur, Malaysia \\ ${ }^{2}$ Department of Molecular Medicine, Faculty of Medicine, University of Malaya, 50603 Kuala Lumpur, Malaysia
}

Correspondence should be addressed to K. T. Wong, wongkt@um.edu.my

Received 7 January 2011; Accepted 9 June 2011

Academic Editor: C. Sundaram

Copyright ( $) 2011$ K. T. Wong and K. C. Ong. This is an open access article distributed under the Creative Commons Attribution License, which permits unrestricted use, distribution, and reproduction in any medium, provided the original work is properly cited.

Zoonoses as causes of human infections have been increasingly reported, and many of these are viruses that cause central nervous system infections. This paper focuses on the henipaviruses (family Paramyxoviridae, genus henipavirus) that have recently emerged to cause severe encephalitis and systemic infection in humans and animals in the Asia-Pacific region. The pathological features in the human infections comprise vasculopathy (vasculitis, endothelial multinucleated syncytia, thrombosis, etc.) and parenchymal cell infection in the central nervous system, lung, kidney, and other major organs. Most animals naturally or experimentally infected show more or less similar features confirming the dual pathogenetic mechanism of vasculopathy-associated microinfarction and direct extravascular parenchymal cell infection as causes of tissue injury. The most promising animal models include the hamster, ferret, squirrel monkey, and African green monkey. With increasing evidence of infection in the natural hosts, the pteropid bats and, hence, probable future outbreaks in many more countries, a greater awareness of henipavirus infection in both humans and animals is imperative.

\section{Zoonotic Viruses Associated with Viral Encephalitis}

Numerous emerging infections are zoonoses of known or newly discovered viruses that have jumped the species barrier to infect humans. These include the human immunodeficiency virus (HIV), arboviruses, lyssavirus, henipaviruses, avian, and swine influenza viruses [1-8]. Many of these zoonotic viruses cause severe encephalitis associated with significant mortality and morbidity.

Since its origin has been traced to African nonhuman primates, HIV has become established in human populations [1]. The prevalence of HIV encephalitis is unknown; perhaps hundreds of thousands suffer from this condition since millions of HIV-infected patients still do not have adequate antiretroviral therapy. Among the arboviruses, Japanese encephalitis virus (JEV) infections, transmitted by mosquitoes from birds, is probably the most important, with more than 50,000 patients from the Indian subcontinent and southeast Asia [5]. West Nile virus, another known, similarly transmitted arbovirus, recently emerged to cause human neuroinvasive disease in North America, a region not previously known to be affected $[9,10]$.

Henipavirus genus, a recently established group of paramyxoviruses [11] comprising the Hendra virus (HEV) and Nipah virus (NIV), has emerged to cause severe encephalitis in humans and animals. There are several previous reviews on NiV or henipavirus infections [12-17], but the present one focuses on the epidemiology, clinical features, and comparative pathology in infected humans and animals and also includes some previously unpublished data.

$\mathrm{HeV}$ was first isolated after an outbreak in horses and 2 humans in the town of Hendra, QLD, Australia in 1994. Since then several other small outbreaks involving horses only, or horses and their carers, have been reported only in Australia and mainly in Queensland. Scores of horses and 7 humans (4 fatalities) have been infected so far [17-24]. NiV was named after the Nipah River village in Malaysia, very soon after the first known outbreak occurred mainly around pig farms from 1989 to 1999. Although a prevalence of 265 Malaysian cases of acute NiV encephalitis with 105 fatalities has been reported [25], the subsequent spread of the virus 
to Singapore and its ability to cause mild infections [26] suggested that the total number infected was probably more than 350 cases [14]. After the outbreak was controlled in Malaysia and Singapore in1999, at the beginning of 2001, several recurrent NiV outbreaks were reported from Bangladesh and the adjacent Bengal area of India [27, 28] that have involved more than 120 people thus far.

\section{Henipavirus Transmission}

The natural host of henipaviruses is the fruit bat (Pteropus species or "flying foxes") [29-31], and bat-to-human transmission may be direct or indirect via intermediate hosts. The horse is the main if not the only intermediate host for $\mathrm{HeV}$ transmission $[18,23,24]$. Numerous other domestic animals and wildlife investigated were negative for naturally acquired $\mathrm{HeV}$ infection [21]. Contact with virus in horse oronasal secretions and urine appears to be the most likely route of transmission $[32,33]$. Although person-to-person $\mathrm{HeV}$ transmission has not been reported, involvement of the lung and kidney in acute infection and presence of virus in nasopharyngeal secretions strongly suggest this possibility. The natural mode of bat-to-horse transmission remains unclear and unproven experimentally [32]. It was suggested that ingestion of feed or pasture contaminated by bat-derived foetal tissues or urine may be responsible.

In the Malaysia/Singapore outbreak, the pig was the main intermediate host and human transmission was strongly linked to close contact with pigs or fresh pig products [25, 34-37]. Massive culling of sick pigs and banning of exports stopped the epidemic $[36,38]$. Similar to $\mathrm{HeV}$, demonstration of virus in oropharyngeal/respiratory secretions suggests spread by either direct contact or aerosols $[39,40]$. In contrast, absence of virus in pig urine could indicate that spread via urine may be inefficient. It was suggested that bat-to-pig transmission could have resulted from ingestion of half-eaten contaminated fruits dropped by bats near farms [29].

Person-to-person transmission in the Malaysian hospital setting is probably very low, but a nurse could have been infected from patients' tracheal secretions or urine [41-44]. There is no documentation of such transmission among and between farm workers and their families, but this remained a distinct possibility. In contrast, in the Bangladesh/India outbreaks, there was a high incidence of person-to-person transmission involving health care workers or other people $[28,45,46]$. No animals have been positively identified as intermediate hosts although there were associations with sick cows, pigs, and goats $[45,47]$ Bat-contaminated, date palm sap drunk raw as a local delicacy has been implicated in some cases of bat-to human transmissions in Bangladesh [48].

\section{Clinical Aspects of Henipavirus Infection}

The incubation period ranges from a few days to 2 weeks [ 19 , 23, 24, 49, 50]. Milder symptoms include fever, headache, influenza-like illness, and drowsiness. Severe $\mathrm{HeV}$ infection, may present either as a neurological or a pulmonary syndrome, but since there have been very few patients, the clinical features were not well characterized. Neurological signs include confusion, motor deficits and seizures while the pulmonary syndrome presents with an influenza-like illness, hypoxaemia, and diffuse alveolar shadowing in chest X-Rays $[23,24]$

Severe NiV encephalitic syndrome presents mainly with fever, headache, dizziness, vomiting, and reduced consciousness [50]. Clinical signs such as areflexia, hypotonia, abnormal pupillary and doll's eye reflex, tachycardia, hypertension, myoclonus, meningism, and convulsions were observed. A pulmonary syndrome has been described in some patients who present with cough, atypical pneumonia, and abnormal chest X-Ray findings [49-51]. Brain MR scans in acute henipavirus encephalitis show typical, disseminated, small discrete hyperintense lesions in both grey and white matter $[23,52,53]$.

Specific antihenipavirus antibodies that can be detected in the serum and cerebrospinal fluid (CSF) in most patients are critical to diagnosis. More is known about seroconversion after $\mathrm{NiV}$ infection than $\mathrm{HeV}$ infection. In $\mathrm{NiV}$ infection, IgM seroconversion by about 2 weeks was $100 \%$ and persisted for more than 3 months. IgG seroconversion was 100\% by about 3 weeks and may persist for several years [54, 55]. Specific neutralizing IgM or IgG antibodies have been reported in $\mathrm{HeV}$-infected patients [19, 20, 24].

CSF examination showed elevated protein levels and/or white cell counts in more than $75 \%$ of NiV patients, but glucose levels were normal $[50,56]$. Electroencephalography most commonly showed continuous, diffuse, symmetrical slowing with or without focal discharges in acute $\mathrm{NiV}$ encephalitis [57].

Mortality in $\mathrm{HeV}$ infection is about $50 \%$, while in severe $\mathrm{NiV}$ infection it ranges from about $40 \%$ (Malaysia) to $70 \%$ (Bangladesh/India) $[25,27,28]$. In acute NiV encephalitis, brainstem involvement, presence of virus in the CSF, and diabetes mellitus are poor prognostic indicators $[50,58,59]$. The majority of Malaysian patients apparently recovered with no serious sequelae. However, henipavirus infection may be complicated by relapsing encephalitis after initial recovery. One case of relapsing $\mathrm{HeV}$ encephalitis and more than 20 cases of relapsing NiV encephalitis (probably $<10 \%$ of survivors) have been reported thus far $[20,26]$. The single case of relapsing $\mathrm{HeV}$ encephalitis occurred about 13 months after exposure, while an average of 8 months elapsed before relapsing NiV encephalitis occurred. Some cases of relapsing $\mathrm{NiV}$ encephalitis only had fever and headache during the acute phase and have also been called "late-onset" encephalitis. Clinical, radiological, and pathological findings suggest that relapsing $\mathrm{NiV}$ encephalitis is distinct from acute $\mathrm{NiV}$ encephalitis and that relapsing henipavirus encephalitis is the result of viral recrudescence $[13,26,52,60]$.

\section{Pathology of Acute Henipavirus Infection in Humans}

Although published data on $\mathrm{HeV}$ infection consists of a single case and most of the information on human henipavirus infection is derived from $\mathrm{NiV}$ studies, we believe both viruses cause essentially the same pathology. Acute infection 


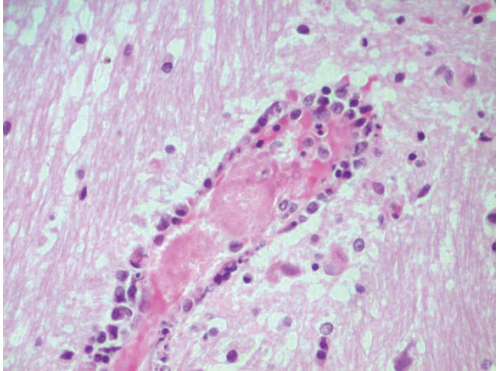

(a)

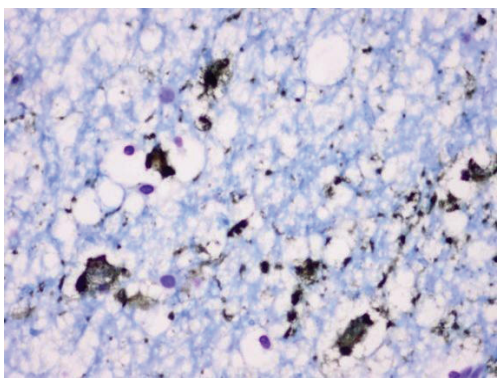

(c)

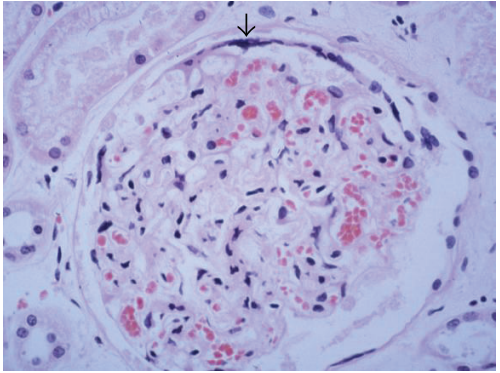

(e)

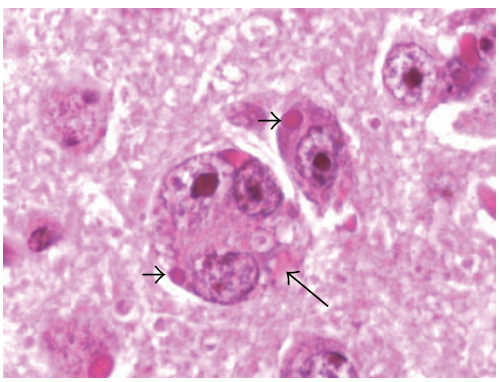

(g)

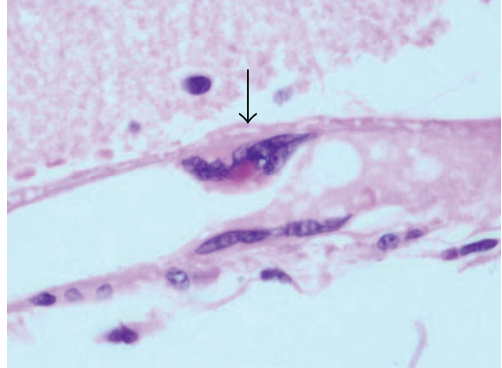

(b)

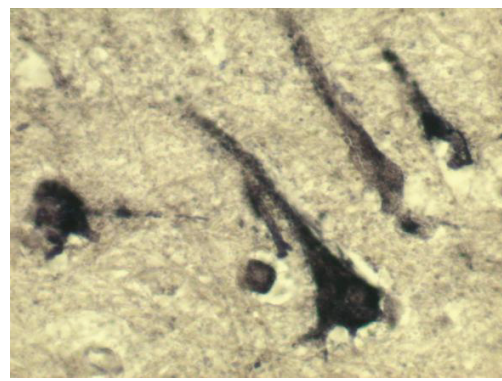

(d)

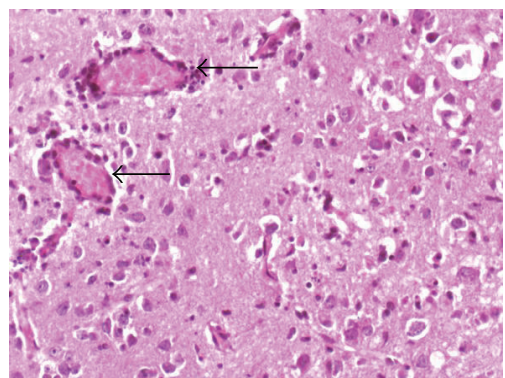

(f)

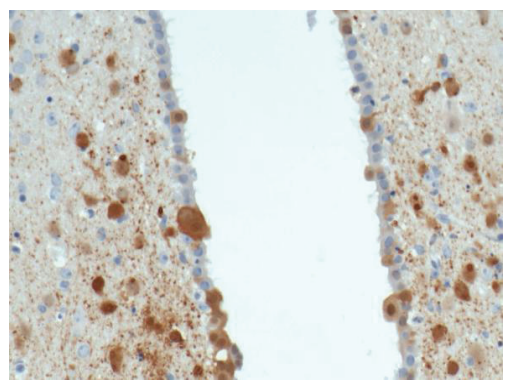

(h)

FIGURE 1: Pathology of human and hamster henipavirus infection. (a) Vasculitis and associated intravascular thrombosis in human brain. (b) In an uninflamed meningeal vessel, a multinucleated giant cell (arrow) with viral inclusion arises from the endothelial surface. (c) Neuronal viral antigens in human Nipah infection. (d) Neuronal viral RNA in human Hendra infection. (e) Glomerulus in human Nipah infection with thrombosis, necrosis, and peripheral multinucleated giant cell formation (arrowhead). (f) Mild vasculitis (arrows) and encephalitis in Nipah-infected hamster brain. (g) Viral inclusions in neurons (arrowheads) and the rare neuronal syncytia (arrow) in Nipah-infected hamster brain. (h) Nipah viral antigens in neurons and ependymal cells in infected hamster. (h and e) stains (a, b, e, f, g), immunoperoxidase stains (c, h), in situ hybridisation (d). Magnification, objective $\times 20(\mathrm{a}, \mathrm{c}, \mathrm{f}, \mathrm{h}), \times 40(\mathrm{~b}, \mathrm{~d}, \mathrm{e}, \mathrm{g})$.

is characterized by disseminated small vessel vasculopathy comprising true vasculitis, endothelial ulceration, and intramural necrosis in the central nervous system (CNS), lung, kidney, and many other major organs (Figure 1) [60, 61]. Occasionally, endothelial multinucleated giant cells or syncytia may be detected (Figure 1(b)). Vascular occlusion by vasculitis-induced thrombosis (Figure 1(a)) and perivascular haemorrhage were observed. Viral antigens, RNA, and nucleocapsids could be detected in vascular endothelium, multinucleated giant cells, and smooth muscle $[61,62]$.

In NiV infection, CNS vasculopathy was most severe compared to other organs. Vasculopathy was often associated 
with discrete necrotic or more subtle vacuolar plaque-like lesions that corresponded with lesions seen in the MR scans. These lesions were characterized by necrosis, oedema, and inflammation, and often viral antigens (Figure 1(c)) and RNA (Figure $1(\mathrm{~d})$ ) were demonstrable in adjacent neurons [60]. Hence, it is believed that both microinfarction and neuronal infection give rise to necrotic plaques. In some cases, focal neuronophagia, microglial nodule formation, clusters of foamy macrophages, perivascular cuffing, and meningitis can be found. A more extensive review of the CNS pathology has been published elsewhere [13]. In the lung, kidney (Figure 1(e)), lymphoid organs, and so forth, vasculopathy, parenchymal inflammation, and necrosis with occasional multinucleated giant cells were also observed [60, 61].

\section{Pathology of Acute Henipavirus Infection in Animals}

Consistent with in vitro experiments that showed extensive infectivity of henipaviruses in different cell lines [63], natural or in vivo experimental infections on a variety of mammalian species have been reported. The table summarises these findings and is organized on the assumption that henipaviruses as a group probably causes similar pathology in the same animal species. We are aware there may yet be differences between $\mathrm{HeV}$ and $\mathrm{NiV}$ infections in the same animal, but to date there is no published study that directly compares these viruses under identical experimental conditions.

Animals naturally infected by henipaviruses and whose tissues have been examined for pathological changes are few and include the dog, cat, horse, and pig [32, 40, 66, 84]. Hooper et al. described pulmonary inflammation and glomerular and tubular necrosis associated with syncytia formation in NiV-infected dogs [67]. We examined two naturally infected dogs and found pulmonary vasculitis (Figure 2(a)), alveolar oedema, and inflammation (unpublished data). In the kidney, many glomeruli and adjacent tubules were thrombosed or necrotic with varying degrees of inflammation (Figure 2(b)). Viral antigens and RNA were demonstrated (Figure 2(c)). Serological studies confirmed that the dog is susceptible to NiV infection [71], but susceptibility to $\mathrm{HeV}$ was inconclusive $[21,68]$. Nonsuppurative meningitis, cerebral ischaemia and vasculopathy have been described, but there is no published data on direct neuronal infection [67].

The cat is very susceptible to henipavirus infection under natural or experimental conditions. Vasculopathy consisting of vasculitis, endothelial syncytia, and viral immunolocalisation in endothelium and vascular smooth muscle was observed in many organs, except perhaps in the brain parenchyma, but meninges were involved (Table 1). There is severe pulmonary inflammation, and bronchial epithelium involvement may be prominent $[40,66,67,69]$. Lymphoid tissues, such as the spleen, lymph nodes, thymus, and Peyer's patches, and kidney parenchymal tissues including glomeruli were often involved.

The horse as the intermediate host of $\mathrm{HeV}$ develops both a pulmonary and an encephalitic syndrome $[18,33]$, the latter being recognized only more recently. As in other infected animals, systemic vasculopathy is a prominent feature in the lungs, CNS, kidney, and other organs (Table 1). Apart from vasculopathy, observed encephalitis, necrosis and neuronal changes in the CNS suggest direct neuronal infection, but surprisingly so far there are no published reports to confirm this [67].

Naturally NiV-infected pigs develop a distinctive clinical syndrome called "porcine respiratory and encephalitis syndrome" or "barking pig syndrome" [85]. As the latter name suggests, pigs can develope a characteristic loud barking cough, which differs from other known porcine respiratory diseases. Respiratory distress was also observed in pigs experimentally infected with henipaviruses $[39,81]$. Neurological signs included paralysis and abnormal movement and gait. Many pigs however may remain asymptomatic or, having developed clinical signs and symptoms, recover to a large extent [85].

In studies of both natural and experimental pig infections that we (unpublished data) and others have done, the most severe pathology appears to be found in the respiratory system [39, 40, 81-83]. There was evidence of tracheitis, bronchial inflammation, and pneumonia. Numerous macrophages, neutrophils, and multinucleated cells can be found within alveoli (Figures 2(d) and 2(e)) and bronchioles. Epithelial syncytia arising from the bronchial epithelium are prominent, and viral antigens and RNA (unpublished data) could be demonstrated (Figures 2(f) and 2(h)). Vasculitis and multinucleated syncytial cells were seen in small blood vessels (Figure 2(i)). Meningitis was characterised by vasculitis, inflammation, and viral antigens localised to the arachnoid membrane [40,67]. Overall, encephalitis was thought to be rare, but neuronal and peripheral nerve infections have been demonstrated [39, 82]. Peripheral nerves may play a role in viral transmission into the CNS, a phenomenon suggested so far only in the pig.

Several other animals that have been experimentally infected successfully include the guinea pig, hamster, ferret, nonhuman primates (squirrel monkey and African green monkey), and chick embryo (Table 1). The infected guinea pig shows extensive vasculopathy (Table 1) in the urinary bladder, female reproductive tract, lymphoid organs, gastrointestinal tract, brain, and so forth. [64, 65, 74, 75, 84]. Notably, although pulmonary vasculopathy was described [67], the lung generally showed mild inflammation. Viral antigens and inclusions could be localised to neurons [74], but higher viral doses may be needed to produce encephalitis and/or neuronal infection [75]. Hamster tissues infected by henipaviruses generally showed systemic vasculopathy and parenchymal lesions in most major CNS and non-CNS organs examined (Table 1) $[76,77]$. In the CNS, there was encephalitis, and there were viral inclusions, antigens and RNA in the neurons (Figures $1(\mathrm{f})$ and $1(\mathrm{~h})$ ). Very rarely, neuronal syncytia were observed (Figure $1(\mathrm{~g})$ ) (unpublished data). In addition to vasculopathy, pneumonia, glomerulitis and tubular lesions have been described. The squirrel monkey and African green monkey are susceptible by henipaviruses, and results suggest that they are good nonhuman primate animal models. As in the human infection, systemic vasculopathy and involvement of a broad range of organs 


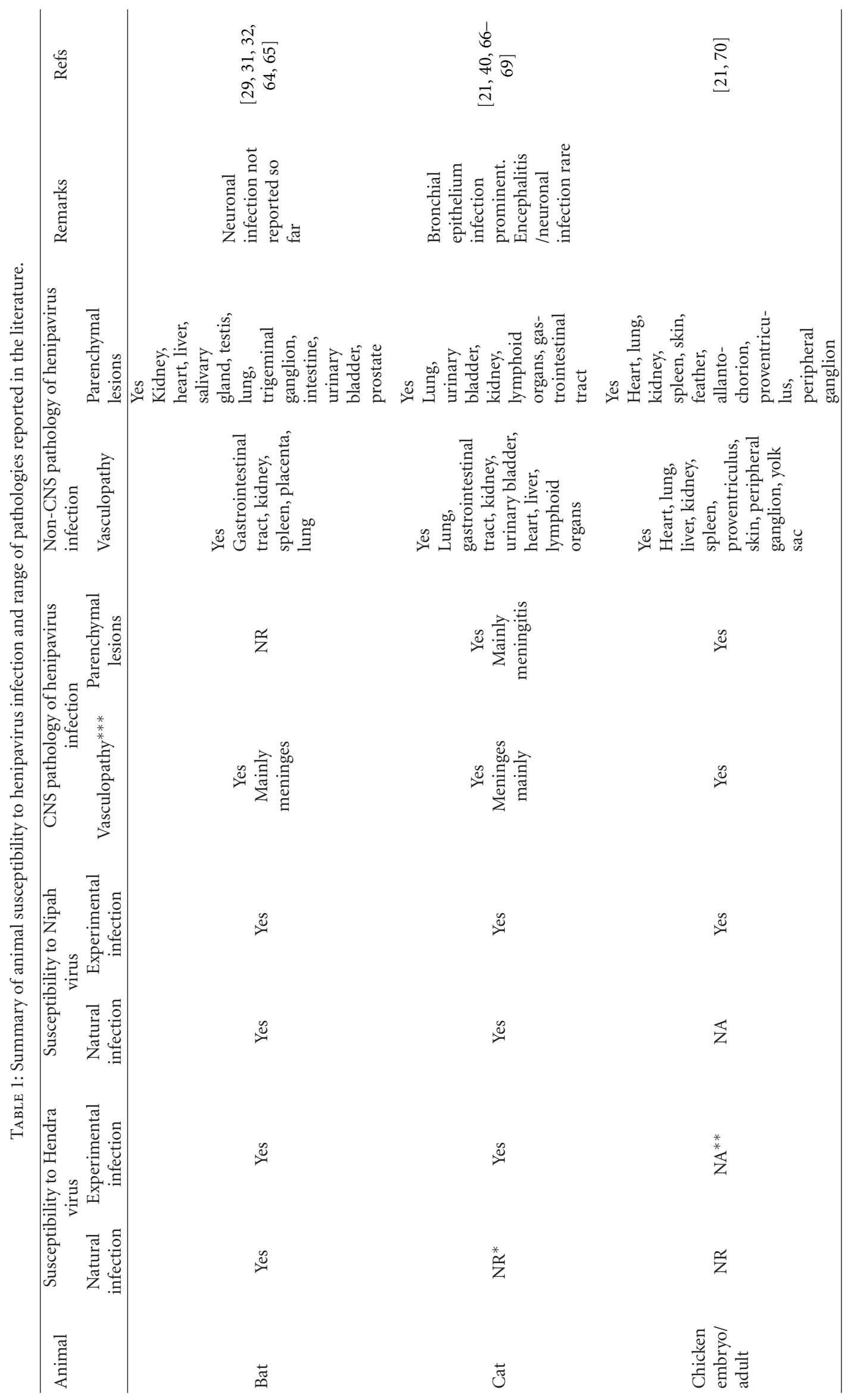




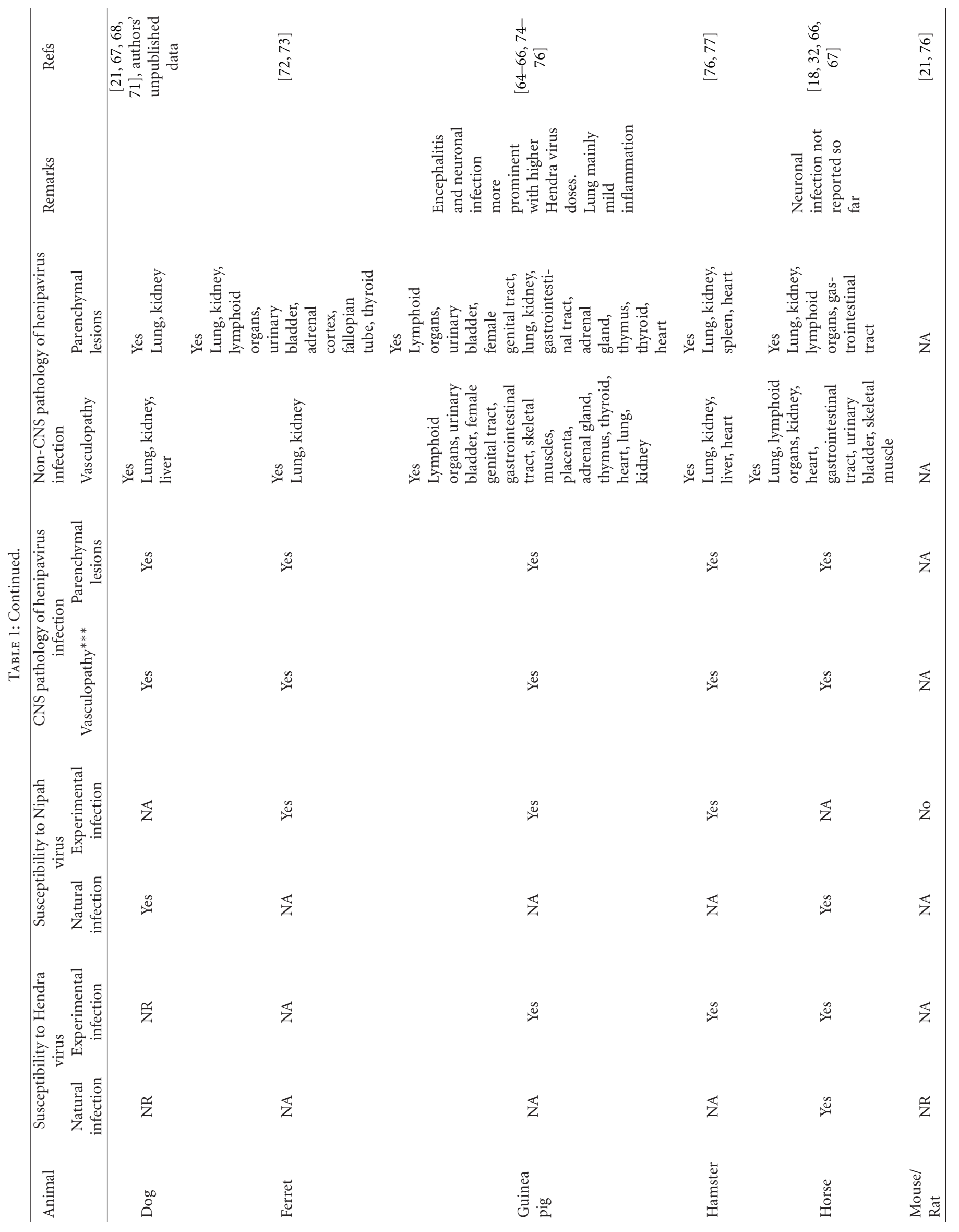




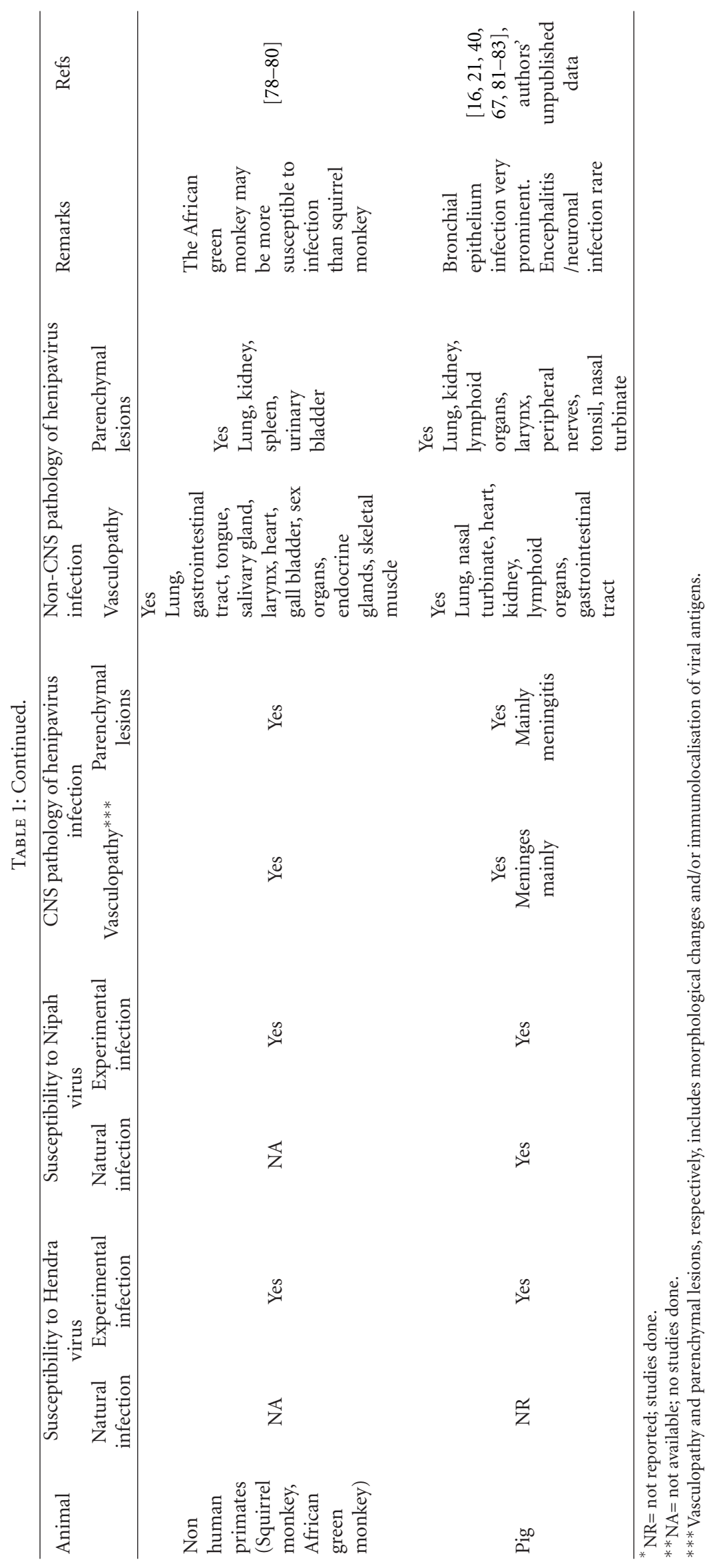




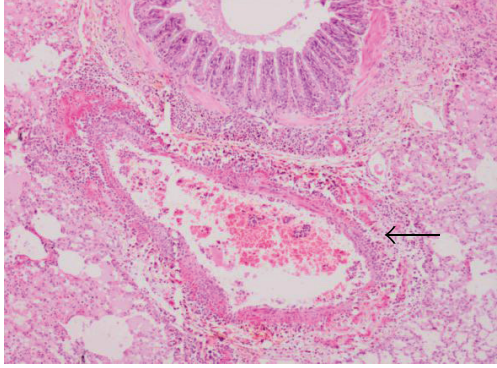

(a)

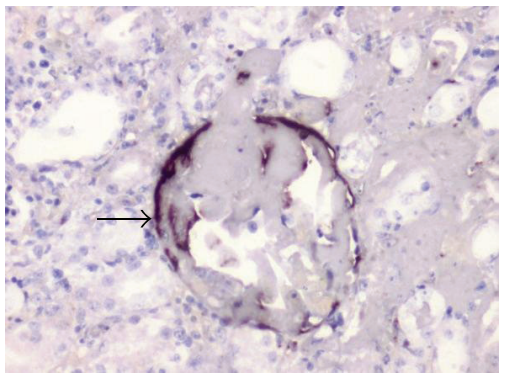

(c)

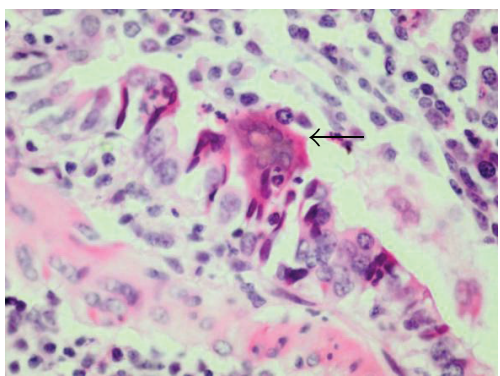

(f)

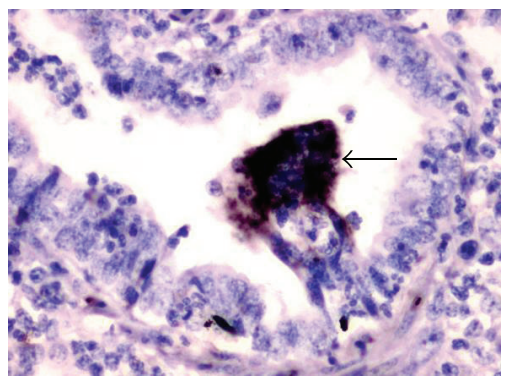

(h)

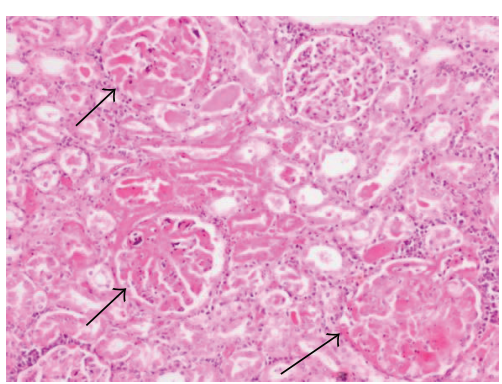

(b)

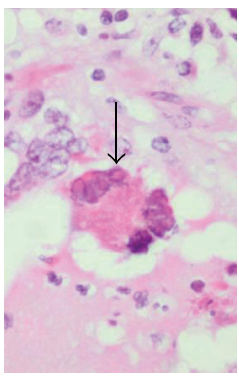

(d)

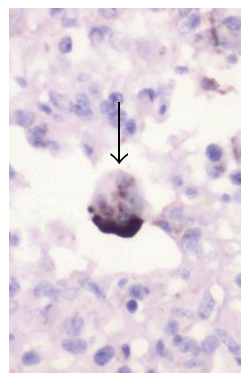

(e)

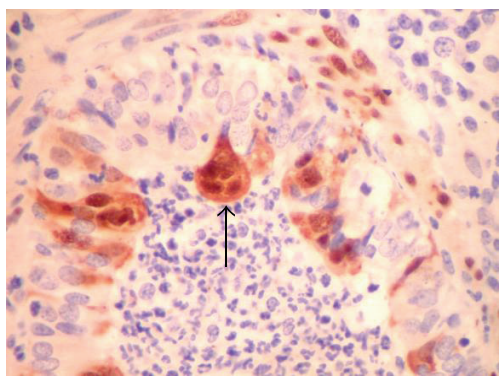

(g)

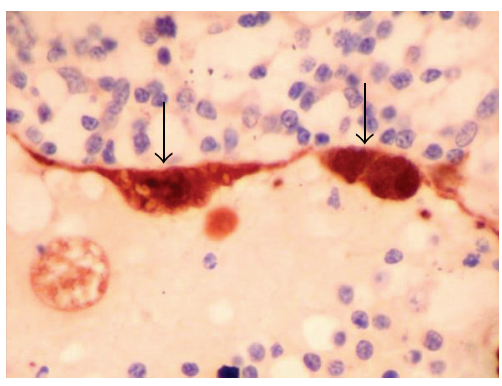

(i)

Figure 2: Pathology of dog and pig henipavirus infection. (a) Pulmonary vasculitis (arrow) and oedema in the Nipah-infected dog lung. (b) Glomerular (arrow) and tubular necrosis in the dog kidney. (c) Nipah viral RNA in dog glomerulus (arrow). Intra-alveolar multinucleated giant cell containing Nipah viral inclusions (d) (arrow) and viral RNA (e) (arrow). Bronchiolar syncytia (f) (arrow), viral antigens (g) (arrow) and RNA (h) (arrow) in Nipah-infected pig lung. Endothelial giant cell in pig pulmonary vessel (i) (arrows). (h and e) stains (a, b, d, f), immunoperoxidase stains (g, i), in situ hybridisation (c, e, h). Magnification, objective $\times 4$ (a), $\times 10$ (b), $\times 20(c), \times 40(d-i)$.

were detected (Table 1) [78-80]. More detailed analysis of the pathological features in these models should enable the pathogenesis of henipavirus infection to be further investigated. Pathological data from the infected ferret shows systemic vasculopathy and parenchymal lesions in the CNS and non-CNS organs (Table 1) $[72,73]$. The chick embryo also shows evidence of extensive CNS and non-CNS involvement suggesting that adult birds may also be susceptible to henipaviruses, but so far there is no data available [70].

As the natural reservoir host of henipaviruses, it is not surprising that experimentally infected bats did not develop severe disease nor severe pathological changes (Table 1) 
$[64,65]$. Interestingly, mouse and rat do not apparently develop clinical disease for reasons yet to be investigated [76].

In general, the pathology described in various animal species reflects the pathological features seen in the human disease, namely, extensive vasculopathy, parenchymal lesions in multiple organs, and evidence of viral infection. However, there may be some significant differences among animals. In the pig and cat, respiratory tract involvement, notably of the bronchial epithelium, stands out as a prominent feature. In contrast, the guinea pig shows mild lung parenchymal inflammation. Encephalitis and/or neuronal infection may be more subtle in the pig and cat in contrast to human infection.

The pathological findings in the respiratory tracts of the horse and pig, particularly the latter, are of course consistent with the postulated modes of viral transmission to humans via oropharyngeal/respiratory fluids and aerosols. Interestingly, negative virus isolation from pig urine suggests inefficient viral spread by this means $[39,81]$ though rare involvement of the glomerulus still suggests this possibility [40]. We were unable to demonstrate glomerular or tubular pathology in the 2 pigs that we have examined (unpublished data). Thus, respiratory tract secretions may be the main mode of pig-to-human NiV transmission. On the other hand, extensive kidney involvement in dogs and cats, implicated as minor intermediate hosts, may be via contaminated urine and in cats via respiratory secretions as well $[25,67,71,86]$.

If one considers as a prerequisite for a good animal model encephalitis and neuronal involvement in the CNS, in addition to systemic vasculopathy and severe inflammation in the lung, kidney, and other major organs, then perhaps the hamster, ferret, and monkey represent the best available small animal models of henipavirus infection. Although it is difficult to directly compare the relative susceptibility of these animals to henipaviruses as the viral sources and doses, inoculation routes, and animal and environmental characteristics may be different, perhaps among the nonhuman primates, the African green monkey could be more susceptible than the squirrel monkey. Nonetheless, all these models could be useful models for pathogenesis, therapeutic and vaccine studies as have already been done [77, 79, 87]. Overall, all the animal models confirm the dual pathogenetic mechanisms postulated for tissue injury in henipavirus infection, namely, vasculopathy-associated microinfarction and direct viral infection of extravascular parenchymal cells [61].

It is perhaps not surprising that henipaviruses cause similar infectious disease pathology in both humans and animals as it has now been shown that they share the same virus entry receptor. The main receptor has been identified as ephrin B2 $[88,89]$, and the alternative receptor is ephrin B3 [90]. These receptors are ubiquitous on plasma membranes of many mammalian cells, particularly in the blood vessels and $\mathrm{CNS}$, thus accounting for the prominent clinic pathological features of vasculitis and CNS involvement.

The emergence of henipaviruses over a short period of a few years underscores the growing importance of this group of viruses as causative agents of previously unknown zoonoses. Because pteropid bats as natural hosts are found in many parts of the world, future henipavirus outbreaks should be anticipated [29, 30, 91-95].

\section{Addendum}

A very recent comparative study of $\mathrm{NiV}$ and $\mathrm{HeV}$ in the hamster model (Rockx et al. [96]) showed that while the type of pathological lesions was essentially similar between the two, there were differences in respiratory tract replication sites and the onset and severity of pathological lesions. HeV-induced lesions were found to appear earlier and were more severe.

\section{Acknowledgment}

The authors gratefully acknowledge Dr. Peter Daniels, CSIRO, Australia, for making available to us the dog and pig tissues for histopathological analysis.

\section{References}

[1] E. C. Holmes, "On the origin and evolution of the human immunodeficiency virus (HIV)," Biological Reviews of the Cambridge Philosophical Society, vol. 76, no. 2, pp. 239-254, 2001.

[2] J. S. M. Peiris, W. C. Yu, C. W. Leung et al., "Re-emergence of fatal human influenza A subtype H5N1 disease," The Lancet, vol. 363, no. 9409, pp. 617-619, 2004.

[3] CDC, "Isolation of avian influenza (H5N1) viruses from humans-Hong Kong, May-December 1997," Morbidity and Mortality Weekly Report, vol. 46, no. 50, pp. 1204-1207, 1997.

[4] CDC, "Outbreak of West Nile-like viral encephalitis-New York, 1999," Morbidity and Mortality Weekly Report, vol. 48, pp. 845-849, 1999.

[5] L. Kabilan, R. Rajendran, N. Arunachalam et al., "Japanese encephalitis in India: an overview," Indian Journal of Pediatrics, vol. 71, no. 7, pp. 609-615, 2004.

[6] E. Bautista, T. Chotpitayasunondh, Z. Gao et al., "Clinical aspects of pandemic 2009 influenza a (H1N1) virus infection," New England Journal of Medicine, vol. 362, no. 18, pp. 1708$1719,2010$.

[7] “Rabies, Asia,” Weekly Epidemiological Record, vol. 76, no. 41, pp. 320-323, 2001.

[8] M. C. Schneider, P. C. Romijn, W. Uieda et al., "Rabies transmitted by vampire bats to humans: an emerging zoonotic disease in Latin America?" Revista Panamericana de Salud Publica, vol. 25, no. 3, pp. 260-269, 2009.

[9] R. S. Lanciotti, J. T. Roehrig, V. Deubel et al., "Origin of the West Nile virus responsible for an outbreak of encephalitis in the Northeastern United States," Science, vol. 286, no. 5448, pp. 2333-2337, 1999.

[10] N. P. Lindsey, J. E. Staples, J. A. Lehman, and M. Fischer, "Surveillance for human west Nile virus disease-United States, 1999-2008," Morbidity and Mortality Weekly Report, vol. 59, no. 2, pp. 1-17, 2010.

[11] L. F. Wang, M. Yu, E. Hansson et al., “The exceptionally large genome of Hendra virus: support for creation of a new genus within the family Paramyxoviridae," Journal of Virology, vol. 74, no. 21, pp. 9972-9979, 2000.

[12] K. T. Wong, "Emerging and re-emerging epidemic encephalitis: a tale of two viruses," Neuropathology and Applied Neurobiology, vol. 26, no. 4, pp. 313-318, 2000. 
[13] K. T. Wong, "Emerging epidemic viral encephalitides with a special focus on henipaviruses," Acta Neuropathologica, vol. 120, no. 3, pp. 317-325, 2010.

[14] K. T. Wong, W. J. Shieh, S. R. Zaki, and C. T. Tan, "Nipah virus infection, an emerging paramyxoviral zoonosis," Springer Seminars in Immunopathology, vol. 24, no. 2, pp. 215-228, 2002.

[15] C. T. Tan and K. T. Wong, "Nipah encephalitis outbreak in Malaysia," Annals of the Academy of Medicine Singapore, vol. 32, no. 1, pp. 112-117, 2003.

[16] H. M. Weingartl, Y. Berhane, and M. Czub, "Animal models of henipavirus infection: a review," Veterinary Journal, vol. 181, no. 3, pp. 211-220, 2009.

[17] M. M. Williamson and F. J. Torres-Velez, "Henipavirus: a review of laboratory animal pathology," Veterinary Pathology, vol. 47, no. 5, pp. 871-880, 2010.

[18] K. Murray, P. Selleck, P. Hooper et al., "A morbillivirus that caused fatal disease in horses and humans," Science, vol. 268, no. 5207, pp. 94-97, 1995.

[19] J. N. Hanna, W. J. McBride, D. L. Brookes et al., "Hendra virus infection in a veterinarian," Medical Journal of Australia, vol. 185 , no. 10 , pp. 562-564, 2006.

[20] J. D. O'Sullivan, A. M. Allworth, D. L. Paterson et al., "Fatal encephalitis due to novel paramyxovirus transmitted from horses," The Lancet, vol. 349, no. 9045, pp. 93-95, 1997.

[21] R. J. Rogers, I. C. Douglas, F. C. Baldock et al., "Investigation of a second focus of equine morbillivirus infection in coastal Queensland," Australian Veterinary Journal, vol. 74, no. 3, pp. 243-244, 1996.

[22] H. E. Field, P. C. Barratt, R. J. Hughes, J. Shield, and N. D. Sullivan, "A fatal case of Hendra virus infection in a horse in north Queensland: clinical and epidemiological features," Australian Veterinary Journal, vol. 78, no. 4, pp. 279-280, 2000.

[23] E. G. Playford, B. McCall, G. Smith et al., "Human Hendra virus encephalitis associated with equine outbreak, Australia, 2008," Emerging Infectious Diseases, vol. 16, no. 2, pp. 219-223, 2010.

[24] L. A. Selvey, R. M. Wells, J. G. McCormack et al., "Infection of humans and horses by a newly described morbillivirus," Medical Journal of Australia, vol. 162, no. 12, pp. 642-645, 1995.

[25] U. D. Parashar, L. M. Sunn, F. Ong et al., "Case-control study of risk factors for human infection with a new zoonotic paramyxovirus, Nipah virus, during a 1998-1999 outbreak of severe encephalitis in Malaysia," Journal of Infectious Diseases, vol. 181, no. 5, pp. 1755-1759, 2000.

[26] C. T. Tan, K. J. Goh, K. T. Wong et al., "Relapsed and lateonset Nipah encephalitis," Annals of Neurology, vol. 51, no. 6, pp. 703-708, 2002.

[27] M. J. Hossain, E. S. Gurley, J. M. Montgomery et al., "Clinical presentation of Nipah virus infection in Bangladesh," Clinical Infectious Diseases, vol. 46, no. 7, pp. 977-984, 2008.

[28] A. K. Harit, R. L. Ichhpujani, S. Gupta et al., "Nipah/Hendra virus outbreak in Siliguri, West Bengal, India in 2001," Indian Journal of Medical Research, vol. 123, no. 4, pp. 553-560, 2006.

[29] K. B. Chua, C. L. Koh, P. S. Hooi et al., "Isolation of Nipah virus from Malaysian Island flying-foxes," Microbes and Infection, vol. 4, no. 2, pp. 145-151, 2002.

[30] K. Halpin, P. L. Young, H. E. Field, and J. S. Mackenzie, "Isolation of Hendra virus from pteropid bats: a natural reservoir of Hendra virus," Journal of General Virology, vol. 81, no. 8, pp. 1927-1932, 2000.

[31] J. M. Yob, H. Field, A. M. Rashdi et al., "Nipah virus infection in bats (order Chiroptera) in peninsular Malaysia," Emerging Infectious Diseases, vol. 7, no. 3, pp. 439-441, 2001.
[32] M. M. Williamson, P. T. Hooper, P. W. Selleck et al., "Transmission studies of Hendra virus (equine morbillivirus) in fruit bats, horses and cats," Australian Veterinary Journal, vol. 76, no. 12, pp. 813-818, 1998.

[33] H. Field, K. Schaaf, N. Kung et al., "Hendra virus outbreak with novel clinical features, Australia," Emerging Infectious Diseases, vol. 16, no. 2, pp. 338-340, 2010.

[34] M. Sahani, U. D. Parashar, R. Ali et al., "Nipah virus infection among abattoir workers in Malaysia, 1998-1999," International Journal of Epidemiology, vol. 30, no. 5, pp. 1017-1020, 2001.

[35] G. D. Premalatha, M. S. Lye, J. Ariokasamy et al., "Assessment of Nipah virus transmission among pork sellers in Seremban, Malaysia," Southeast Asian Journal of Tropical Medicine and Public Health, vol. 31, no. 2, pp. 307-309, 2000.

[36] M. H. L. Chew, P. M. Arguin, D. K. Shay et al., "Risk factors for Nipah virus infection among abattoir workers in Singapore," Journal of Infectious Diseases, vol. 181, no. 5, pp. 1760-1763, 2000.

[37] R. Ali, A. W. Mounts, U. D. Parashar et al., "Nipah virus infection among military personnel involved in pig culling during an outbreak of encephalitis in Malaysia, 1998-1999," Emerging Infectious Diseases, vol. 7, no. 4, pp. 759-761, 2001.

[38] CDC, "Update: outbreak of Nipah virus-Malaysia and Singapore, 1999," Morbidity and Mortality Weekly Report, vol. 48, pp. 335-337, 1999.

[39] H. Weingartl, S. Czub, J. Copps et al., "Invasion of the central nervous system in a porcine host by Nipah virus," Journal of Virology, vol. 79, no. 12, pp. 7528-7534, 2005.

[40] D. J. Middleton, H. A. Westbury, C. J. Morrissy et al., "Experimental Nipah virus infection in pigs and cats," Journal of Comparative Pathology, vol. 126, no. 2-3, pp. 124-136, 2002.

[41] K. B. Chua, S. K. Lam, K. J. Goh et al., "The presence of nipah virus in respiratory secretions and urine of patients during an outbreak of nipah virus encephalitis in Malaysia," Journal of Infection, vol. 42, no. 1, pp. 40-43, 2001.

[42] A. W. Mounts, H. Kaur, U. D. Parashar et al., "A cohort study of health care workers to assess nosocomial transmissibility of Nipah virus, Malaysia, 1999," Journal of Infectious Diseases, vol. 183, no. 5, pp. 810-813, 2001.

[43] K.-S. Tan, S. A. Sarji, C.-T. Tan et al., "Patients with asymptomatic Nipah virus infection may have abnormal cerebral MR imaging," Neurological Journal of South East Asia, vol. 5, pp. 69-73, 2000.

[44] C. T. Tan and K. S. Tan, "Nosocomial transmissibility of Nipah virus," Journal of Infectious Diseases, vol. 184, no. 10, p. 1367, 2001.

[45] V. P. Hsu, M. J. Hossain, U. D. Parashar et al., "Nipah virus encephalitis reemergence, Bangladesh," Emerging Infectious Diseases, vol. 10, no. 12, pp. 2082-2087, 2004.

[46] E. S. Gurley, J. M. Montgomery, M. J. Hossain et al., "Personto-person transmission of Nipah virus in a Bangladeshi community," Emerging Infectious Diseases, vol. 13, no. 7, pp. 10311037, 2007.

[47] S. P. Luby, E. S. Gurley, and M. J. Hossain, "Transmission of human infection with nipah virus," Clinical Infectious Diseases, vol. 49, no. 11, pp. 1743-1748, 2009.

[48] S. P. Luby, M. Rahman, M. J. Hossain et al., "Foodborne transmission of Nipah virus, Bangladesh," Emerging Infectious Diseases, vol. 12, no. 12, pp. 1888-1894, 2006.

[49] H. T. Chong, S. R. Kunjapan, T. Thayaparan et al., "Nipah encephalitis outbreak in Malaysia, clinical features in patients from Seremban," Neurological Journal of South East Asia, vol. 5, pp. 61-67, 2000. 
[50] K. J. Goh, C. T. Tan, N. K. Chew et al., "Clinical features of Nipah virus encephalitis among pig farmers in Malaysia," New England Journal of Medicine, vol. 342, no. 17, pp. 1229-1235, 2000.

[51] N. I. Paton, Y. S. Leo, S. R. Zaki et al., "Outbreak of Nipahvirus infection among abattoir workers in Singapore," The Lancet, vol. 354, no. 9186, pp. 1253-1256, 1999.

[52] S. A. Sarji et al., "Magnetic resonance imaging features of Nipah encephalitis," American Journal of Roentgenology, vol. 175, pp. 437-442, 2000.

[53] C. C. T. Lim, K. E. Lee, W. L. Lee et al., "Nipah virus encephalitis: serial MR study of an emerging disease," Radiology, vol. 222, no. 1, pp. 219-226, 2002.

[54] H. T. Chong and C. T. Tan, "Relapsed and late-onset Nipah encephalitis, a report of three cases," Neurological Journal of South East Asia, vol. 8, pp. 109-112, 2003.

[55] V. Ramasundram et al., "Kinetics of IgM and IgG seroconversion in Nipah virus infection," Neurological Journal of South East Asia, vol. 5, pp. 23-28, 2000.

[56] K. E. Lee, T. Umapathi, C. B. Tan et al., "The neurological manifestations of Nipah virus encephalitis, a novel paramyxovirus," Annals of Neurology, vol. 46, no. 3, pp. 428-432, 1999.

[57] N. K. Chew et al., "Electroencephalography in acute Nipah encephalitis," Neurological Journal of South East Asia, vol. 4, pp. 45-51, 1999.

[58] H. T. Chong et al., "Occupational exposure, age, diabetes mellitus and outcome of acute Nipah encephalitis," Neurological Journal of South East Asia, vol. 6, pp. 7-11, 2001.

[59] K. B. Chua, S. K. Lam, C. T. Tan et al., "High mortality in Nipah encephalitis is associated with presence of virus in cerebrospinal fluid," Annals of Neurology, vol. 48, no. 5, pp. 802$805,2000$.

[60] K. T. Wong, T. Robertson, B. B. Ong et al., "Human Hendra virus infection causes acute and relapsing encephalitis," Neuropathology and Applied Neurobiology, vol. 35, no. 3, pp. 296$305,2009$.

[61] K. T. Wong, W. J. Shieh, S. Kumar et al., "Nipah virus infection: pathology and pathogenesis of an emerging paramyxoviral zoonosis," American Journal of Pathology, vol. 161, no. 6, pp. 2153-2167, 2002.

[62] C. S. Goldsmith, T. Whistler, P. E. Rollin et al., "Elucidation of Nipah virus morphogenesis and replication using ultrastructural and molecular approaches," Virus Research, vol. 92, no. 1, pp. 89-98, 2003.

[63] K. N. Bossart, L. F. Wang, M. N. Flora et al., "Membrane fusion tropism and heterotypic functional activities of the Nipah virus and Hendra virus envelope glycoproteins," Journal of Virology, vol. 76, no. 22, pp. 11186-11198, 2002.

[64] D. J. Middleton, C. J. Morrissy, B. M. van der Heide et al., "Experimental Nipah virus infection in pteropid bats (Pteropus poliocephalus)," Journal of Comparative Pathology, vol. 136, no. 4, pp. 266-272, 2007.

[65] M. M. Williamson, P. T. Hooper, P. W. Selleck, H. A. Westbury, and R. F. Slocombe, "Experimental Hendra virus infection in pregnant guinea-pigs and fruit bats (Pteropus poliocephalus)," Journal of Comparative Pathology, vol. 122, no. 2-3, pp. 201207, 2000.

[66] P. T. Hooper, P. J. Ketterer, A. D. Hyatt, and G. M. Russell, "Lesions of experimental equine morbillivirus pneumonia in horses," Veterinary Pathology, vol. 34, no. 4, pp. 312-322, 1997.

[67] P. Hooper, S. Zaki, P. Daniels, and D. Middleton, "Comparative pathology of the diseases caused by Hendra and Nipah viruses," Microbes and Infection, vol. 3, no. 4, pp. 315-322, 2001.
[68] H. A. Westbury, P. T. Hooper, P. W. Selleck, and P. K. Murray, "Equine morbillivirus pneumonia: susceptibility of laboratory animals to the virus," Australian Veterinary Journal, vol. 72, no. 7, pp. 278-279, 1995.

[69] B. A. Mungall, D. Middleton, G. Crameri et al., "Feline model of acute Nipah virus infection and protection with a soluble glycoprotein-based subunit vaccine," Journal of Virology, vol. 80, no. 24, pp. 12293-12302, 2006.

[70] N. Tanimura, T. Imada, Y. Kashiwazaki, and S. H. Sharifah, "Distribution of viral antigens and development of lesions in chicken embryos inoculated with Nipah virus," Journal of Comparative Pathology, vol. 135, no. 2-3, pp. 74-82, 2006.

[71] J. N. Mills, A. N. M. Alim, M. L. Bunning et al., "Nipah virus infection in dogs, Malaysia, 1999," Emerging Infectious Diseases, vol. 15, no. 6, pp. 950-952, 2009.

[72] K. N. Bossart, Z. Zhu, D. Middleton et al., "A neutralizing human monoclonal antibody protects against lethal disease in a new ferret model of acute Nipah virus infection," PLoS Pathogens, vol. 5, no. 10, Article ID e1000642, 2009.

[73] J. Pallister, D. Middleton, G. Crameri et al., "Chloroquine administration does not prevent nipah virus infection and disease in ferrets," Journal of Virology, vol. 83, no. 22, pp. 1197911982, 2009.

[74] F. J. Torres-Velez, W. J. Shieh, P. E. Rollin et al., "Histopathologic and immunohistochemical characterization of nipah virus infection in the guinea pig," Veterinary Pathology, vol. 45, no. 4, pp. 576-585, 2008.

[75] M. M. Williamson, P. T. Hooper, P. W. Selleck, H. A. Westbury, and R. F. S. Slocombe, "A guinea-pig model of hendra virus encephalitis," Journal of Comparative Pathology, vol. 124, no. 4, pp. 273-279, 2001.

[76] K. T. Wong, I. Grosjean, C. Brisson et al., "A golden hamster model for human acute Nipah virus infection," American Journal of Pathology, vol. 163, no. 5, pp. 2127-2137, 2003.

[77] V. Guillaume, K. T. Wong, R. Y. Looi et al., "Acute Hendra virus infection: analysis of the pathogenesis and passive antibody protection in the hamster model," Virology, vol. 387, no. 2, pp. 459-465, 2009.

[78] P. Marianneau, V. Guillaume, K. T. Wong et al., "Experimental infection of squirrel monkeys with Nipah virus," Emerging Infectious Diseases, vol. 16, no. 3, pp. 507-510, 2010.

[79] B. Rockx, K. N. Bossart, F. Feldmann et al., "A novel model of lethal Hendra virus infection in African green monkeys and the effectiveness of ribavirin treatment," Journal of Virology, vol. 84, no. 19, pp. 9831-9839, 2010.

[80] T. W. Geisbert, K. M. Daddario-Dicaprio, A. C. Hickey et al., "Development of an acute and highly pathogenic nonhuman primate model of nipah virus infection," PLOS ONE, vol. 5, no. 5, Article ID e10690, 2010.

[81] M. Li, C. Embury-Hyatt, and H. M. Weingartl, "Experimental inoculation study indicates swine as a potential host for Hendra virus," Veterinary Research, vol. 41, no. 3, p. 33, 2010.

[82] N. Tanimura, T. Imada, Y. Kashiwazaki, S. Shahirudin, S. H. Sharifah, and A. J. Aziz, "Monoclonal antibody-based immunohistochemical diagnosis of Malaysian Nipah virus infection in pigs," Journal of Comparative Pathology, vol. 131, no. 2-3, pp. 199-206, 2004.

[83] N. Tanimura, T. Imada, Y. Kashiwazaki et al., "Reactivity of anti-Nipah virus monoclonal antibodies to formalin-fixed, paraffin-embedded lung tissues from experimental Nipah and Hendra virus infections," Journal of Veterinary Medical Science, vol. 66, no. 10, pp. 1263-1266, 2004. 
[84] P. T. Hooper, H. A. Westbury, and G. M. Russell, "The lesions of experimental equine morbillivirus disease in cats and Guinea pigs," Veterinary Pathology, vol. 34, no. 4, pp. 323-329, 1997.

[85] M. N. M. Nor, C. H. Gan, and B. L. Ong, "Nipah virus infection of pigs in peninsular Malaysia," OIE Revue Scientifique et Technique, vol. 19, no. 1, pp. 160-165, 2000.

[86] K. S. Tan, C. T. Tan, and K. J. Goh, "Epidemiological aspects of Nipah virus infection," Neurological Journal of South East Asia, vol. 4, pp. 77-81, 1999.

[87] V. Guillaume, H. Contamin, P. Loth et al., "Nipah virus: vaccination and passive protection studies in a Hamster model," Journal of Virology, vol. 78, no. 2, pp. 834-840, 2004.

[88] O. A. Negrete, E. L. Levroney, H. C. Aguilar et al., "EphrinB2 is the entry receptor for Nipah virus, an emergent deadly paramyxovirus," Nature, vol. 436, no. 7049, pp. 401-405, 2005.

[89] M. I. Bonaparte, A. S. Dimitrov, K. N. Bossart et al., "EphrinB2 ligand is a functional receptor for Hendra virus and Nipah virus," Proceedings of the National Academy of Sciences of the United States of America, vol. 102, no. 30, pp. 10652-10657, 2005.

[90] O. A. Negrete, M. C. Wolf, H. C. Aguilar et al., "Two key residues in EphrinB3 are critical for its use as an alternative receptor for Nipah virus," PLoS Pathogens, vol. 2, no. 2, article e7, 2006.

[91] J. M. Reynes, D. Counor, S. Ong et al., "Nipah virus in lyle's flying foxes, Cambodia," Emerging Infectious Diseases, vol. 11, no. 7, pp. 1042-1047, 2005.

[92] J. H. Epstein, V. Prakash, C. S. Smith et al., "Henipavirus infection in fruit bats (Pteropus giganteus), India," Emerging Infectious Diseases, vol. 14, no. 8, pp. 1309-1311, 2008.

[93] S. Wacharapluesadee, B. Lumlertdacha, K. Boongird et al., "Bat Nipah virus, Thailand," Emerging Infectious Diseases, vol. 11, no. 12, pp. 1949-1951, 2005.

[94] Y. Li, J. Wang, A. C. Hickey et al., "Antibodies to Nipah or Nipah-like viruses in bats, China," Emerging Infectious Diseases, vol. 14, no. 12, pp. 1974-1976, 2008.

[95] D. T. S. Hayman, R. Suu-Ire, A. C. Breed et al., "Evidence of henipavirus infection in West African fruit bats," PLoS ONE, vol. 3, no. 7, Article ID e2739, 2008.

[96] B. Rockx, D. Brining, J. Kramer et al., "Clinical outcome of Henipavirus infection in hamsters is determined by the route and dose of infection," Journal of Virology, vol. 85, no. 15, pp. 7658-7671, 2011. 


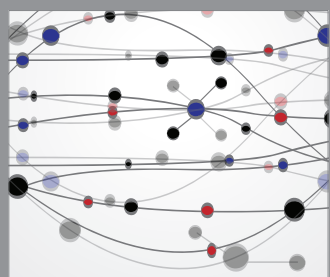

The Scientific World Journal
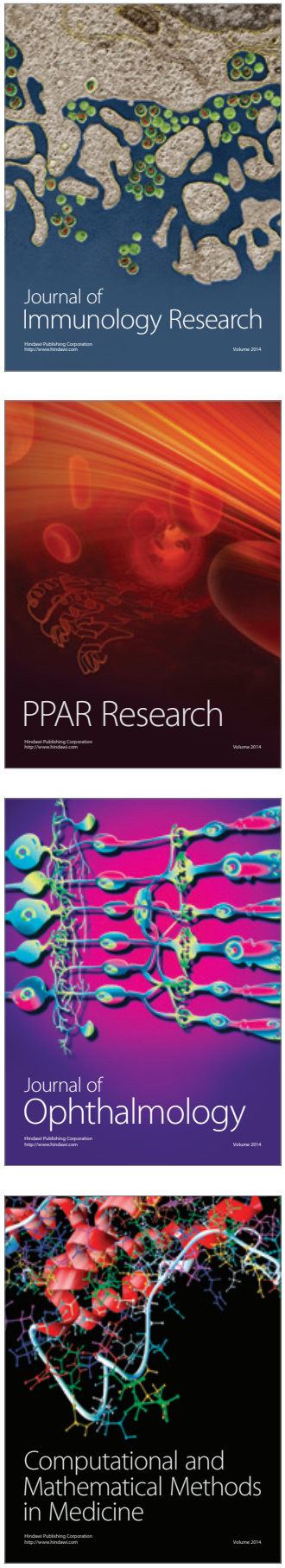

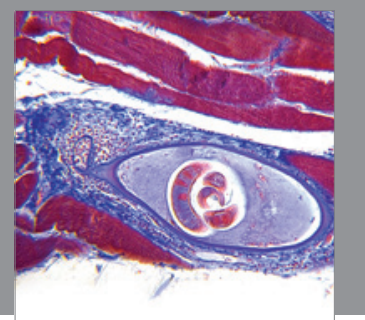

Gastroenterology

Research and Practice
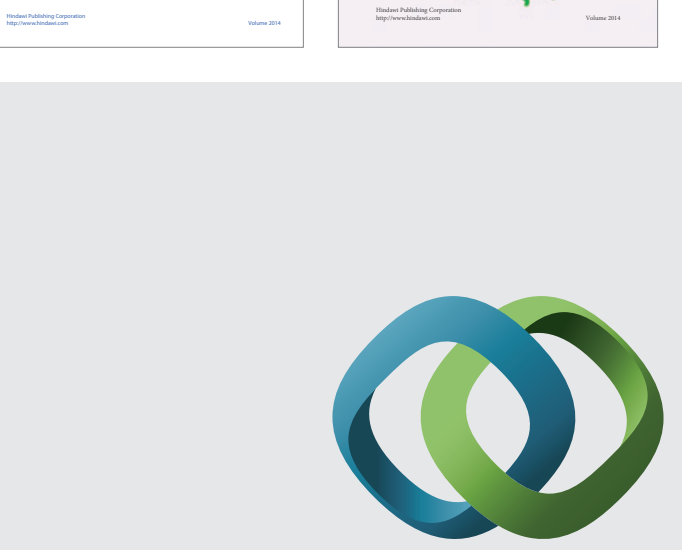

\section{Hindawi}

Submit your manuscripts at

http://www.hindawi.com
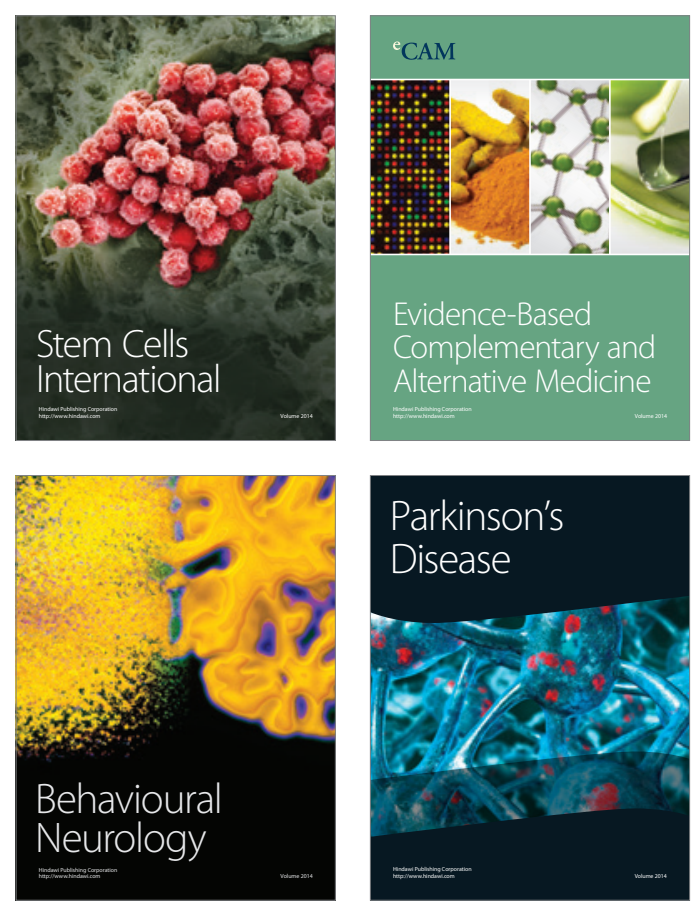

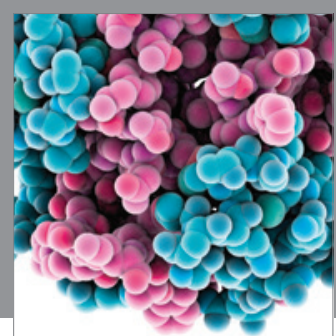

Journal of
Diabetes Research

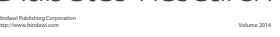

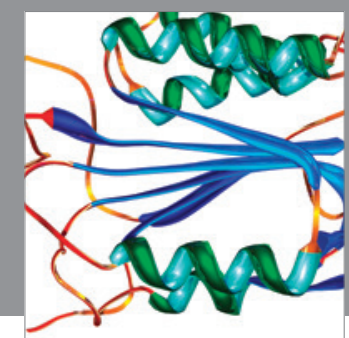

Disease Markers
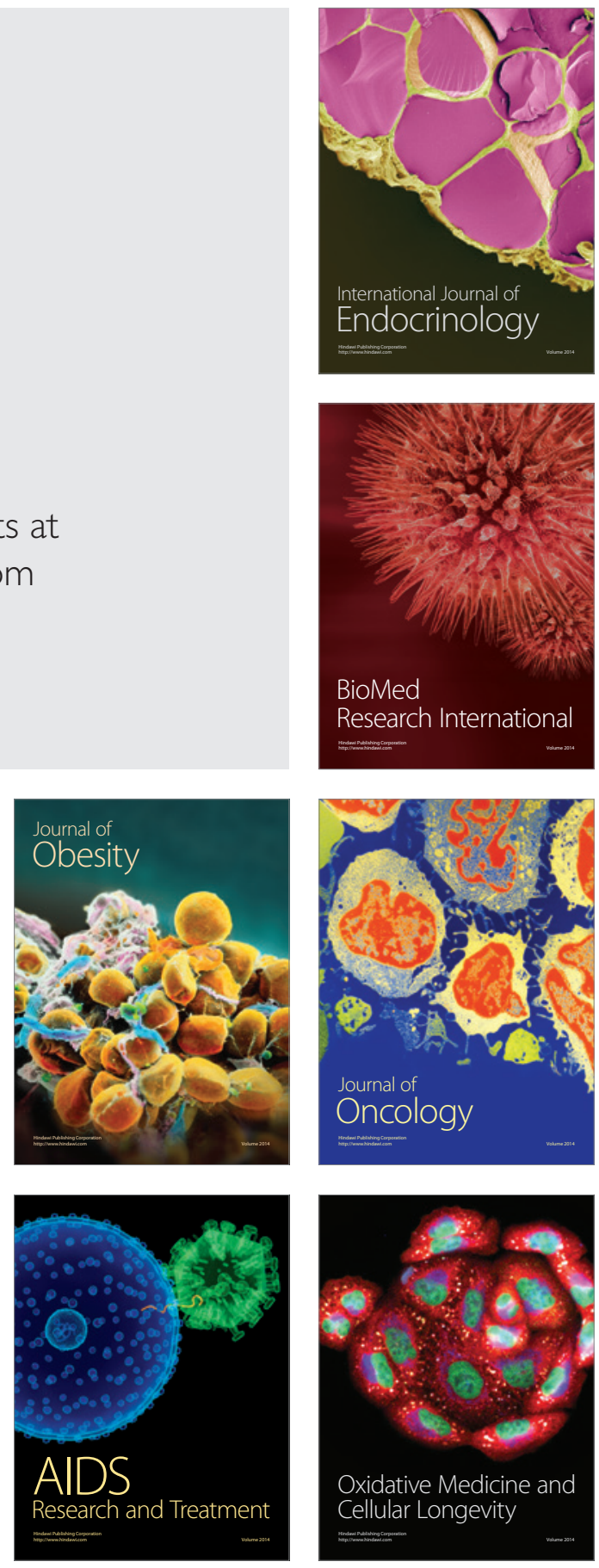